\title{
Post treatment quality of life among Sri Lankan women with breast cancer
}

\author{
Ravindri Jayasinghe, Ashan Fernando, Umesh Jayarajah ${ }^{*}$ (D) and Sanjeewa Seneviratne
}

\begin{abstract}
Background: Breast cancer and its treatment imposes a significant effect in the quality of life (QOL) of women. Being a developing country with contrasting social and cultural norms to the West, Sri Lankan women may have a different experience on QOL following surgical treatment of breast cancer. This study was conducted to evaluate post-treatment QOL in breast cancer patients and to determine its association with the type of surgery.

Methods: A cross sectional study was carried out. Fifty four women with non-metastatic breast cancer who underwent surgery for breast cancer at the Professorial Surgical Unit, Colombo during 2015-2018 and completed a minimum of one year follow up after surgery were invited to participate. Fifty-four women who responded were assessed using the validated EORTC QLQ-C30 and QLQ-BR23 questionnaires. Non-parametric tests were used for statistical analyses.

Results: The mean age was 59 years (range 36-81). A majority $(61 \%, n=35)$ underwent mastectomy and the rest ( $n=19,45 \%$ ) breast conservation surgery (BCS). The mean QLQ-C30 score was 68.8 (range 8.3-100) and the mean scores for physical function, role function, emotional function, cognitive function, and social function were 71.4, $81.5,77.0,80.2$, and 86.4, respectively. The mean scores for body image, sexual functioning, sexual enjoyment, future perspective, systemic therapy, breast symptoms, arm symptoms, and hair loss assessed by the QLQ-BR23 were 76.4, $18.3,33.3,73.6,30.5,16.2,23.4$ and 32.7 , respectively. No significant differences $(P>0.05)$ were noted in global health status, physical function, role function, emotional function, cognitive function and social function between BCS and mastectomy. QLQ-BR23 body image, sexual functioning, sexual enjoyment and future perspective also did not differ significantly $(p>0.05)$ between the two groups.

Conclusions: Sexual functioning and enjoyment, breast and arm symptoms and hair loss contributed to poor QOL while the impact on global health status including physical, social and emotional functions were minimal. Type of surgery did not appear to be associated with QOL. Future studies with a larger sample sizes will be helpful to further study these factors.
\end{abstract}

Keywords: Quality of life, Breast cancer, Mastectomy, Breast-conserving surgery, Sri Lanka

\footnotetext{
* Correspondence: umeshe.jaya@gmail.com

Department of Surgery, Faculty of Medicine, University of Colombo, P.O. Box

271, Kynsey Road, Colombo 8, Western Province, Sri Lanka
}

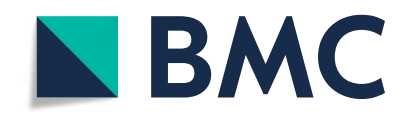

(c) The Author(s). 2021 Open Access This article is licensed under a Creative Commons Attribution 4.0 International License, which permits use, sharing, adaptation, distribution and reproduction in any medium or format, as long as you give appropriate credit to the original author(s) and the source, provide a link to the Creative Commons licence, and indicate if changes were made. The images or other third party material in this article are included in the article's Creative Commons licence, unless indicated otherwise in a credit line to the material. If material is not included in the article's Creative Commons licence and your intended use is not permitted by statutory regulation or exceeds the permitted use, you will need to obtain permission directly from the copyright holder. To view a copy of this licence, visit http://creativecommons.org/licenses/by/4.0/. The Creative Commons Public Domain Dedication waiver (http://creativecommons.org/publicdomain/zero/1.0/) applies to the data made available in this article, unless otherwise stated in a credit line to the data. 


\section{Background}

Breast cancer is the most commonly diagnosed cancer in women with over two million new patients diagnosed in 2018. Furthermore, it is the commonest cause for cancer-related death in women with over 600,000 deaths the same year [1]. In Sri Lanka, breast cancer is the commonest malignancy with an increasing incidence, especially in the post-menopausal women $[2,3]$.

Advancements in diagnosis and treatment have substantially improved the survival rates from breast cancer over last two to three decades with a majority of women achieving a complete cure $[4,5]$. Although these advances would add 'years to patients' lives', it may not add 'life to patients' years' shifting the focus towards improving the quality of life of patients [6]. This has led to post-treatment QOL being recognized as an important issue among the survivors due to the negative impacts of treatment $[6,7]$. QOL in these women is affected not only due to the morbidity linked with the treatment but also due to the additional burden from psychosocial aspects such as changes in lifestyle, sexual dysfunction, and alteration of body image [6].

In the South East Asian region, the evaluation of response to therapy is largely limited to the use of traditional markers such as disease free survival and overall survival. However, worldwide, especially in the West there is an increasing focus towards optimising the health-related quality of life among survivors [8]. The concept of QOL is broad given the complexity of the aspects involved. Health-related quality of life (HRQL) broadly involves the patients' outlook on the impact of illness, impairments, and the impact of therapeutic interventions in the context of quality of life [9]. There are a range of generic and specific instruments developed to assess the quality of life (QOL). As generic instruments are not specific to a particular health condition, specific instruments are made with improved sensitivity to detect changes after an intervention. Amongst the specific instruments available, the instrument developed by the European organization for Research and Treatment of Cancer (EORTC) to evaluate the healthrelated quality of life by a core questionnaire QLQC30 stands out being widely used in literature with proven reliability and reproducibility [10, 11]. The validity of this tool in evaluating health-related quality of life among Sri Lankan women with breast cancer had been proven previously [12].

Two main modes of surgical treatment of breast cancer include breast conservation surgery (BCS) and mastectomy. Evidence has proven BCS followed by whole breast irradiation and total mastectomy to carry nearly equal oncological outcomes in early breast cancer [13]. However, the choice on type of surgery would depend on several patient and disease related factors. Disease related factors such as inflammatory breast cancer, multicentric disease, prior history of radiation to the chest wall, large tumour size in relation to the breast and patient related factors like pregnancy are contraindications for BCS. Furthermore, patients may opt for mastectomy due to several reasons such as fear of recurrence, aversion to radiotherapy and the surgeons' expertise. Breast cancer surgery in most patients would contribute to some degree of both short and longer-term morbidity which may vary depending on patient and tumour factors. A systematic review in 2016 established the negative implications of surgical complications on patient psychosocial outcomes and the QOL [14].

Several studies over the years have focused on QOL after surgery for breast cancer. Although most have shown BCS to be superior to mastectomy, some had shown no significant difference in QOL [15-18]. Several long term follow-up studies have shown no improvement in body image, sexual function over time after BCS versus mastectomy $[15,19]$. Most literature evaluating post-surgical QOL in patients with breast cancer are from the Western world which might significantly differ from the South Asian region due to the sociocultural differences. Even amongst Sri Lankan women, differences are likely to exist depending on the different social, ethnic, and educational groups. Therefore, there is a gap in knowledge in the local context regarding many aspects of QOL after treatment of breast cancer. This study was conducted with the aim of evaluating the post-treatment quality of life (QOL) in breast cancer patients and to determine its association with the type of surgery.

\section{Methods}

A cross sectional study was carried out. Fifty four women with non-metastatic breast cancer who underwent surgery for breast cancer at the Professorial Surgical Unit, Colombo during 2015-2018 and completed a minimum of one year follow up after surgery having an ECOG score of $0-2$ were invited via phone calls and mail to participate in the study. The patients were recruited in the immediate postoperative period and followed up. Only the ones with a follow-up duration of minimum one year were included in the study. Fifty-four women who responded were assessed using the validated EORTC QLQ-C30 and QLQ-BR23 questionnaires. Validated Sinhala, Tamil and English versions of the questionnaires were used [20, 21]. Non-parametric tests were used for statistical analyses.

Women with a previous history of breast or other types of cancer were excluded. Ethical approval for this study was obtained from the Ethical Review Committee, Faculty of Medicine Colombo (EC: 17-126). 
The QLQ-C30 questionnaire includes 30 items to assess five functional scales (physical, cognitive, role, emotional, and social), three symptom scales (Fatigue, pain, nausea and vomiting) and a global health and quality of life scale [10]. QLQ-BR23 includes 23 items including four functional scales and four symptom scales where a higher score in functional scales would represent better functioning and a higher score in symptom scales would indicate increased symptom related issues. Additional data were obtained with regard to the type of surgery $\mathrm{BCS}$ or mastectomy and the menopausal status.

\section{Statistical analysis}

The data were coded and analysed according to the scoring protocol described in the EORTC QLQ-30 manual by Fayers et al. using SPSS version 24 [10, 22]. Nonparametric tests including Chi square $\left(\chi^{2}\right)$ test, MannWhitney U test and Spearman correlation test were used for univariate statistical analyses. QOL scores were compared between women undergoing BCS versus mastectomy. A $p$ value $<0.05$ was considered as statistically significant.

\section{Results}

Fifty-four female patients (16.8\%) from a total of 320 eligible women who had undergone surgery for nonmetastatic breast cancer and consented to participate were included in the study. The mean age was 59.0 years (range $36-81)$ with $61.1 \%(n=33)$ being less than 60 years. Majority of the women were postmenopausal $(85.2 \% \%, n=46)$. A majority $(61.1 \%, n=35)$ underwent mastectomy as the primary surgery and the rest $(45 \%$, $n=19)$ underwent BCS. None of the women who had undergone mastectomy and included in the study had breast reconstruction. Axillary node dissection was performed in 59.2\% $(n=32)$ and the rest only a sentinel lymph node biopsy. The patients had a median followup duration of $>2$ years (Table 1 ).

The mean EORTC QLQ-C30 score was 68.8 (range: 8.3-100) and the mean scores for physical function, role function, emotional function, cognitive function, and social function were 71.4 (range: 33.3-100), 81.5 (range: 0-100), 77 (range: 0-100), 80.2 (range: 33.3-100), 86.4 (range: 0-100), respectively. The EORTC QLQ-C30 scores in the less than 60-year age group $(n=33)$ was not any different than the older patients (greater than or equal to 60 years) (Table 2).

The mean scores for body image, sexual functioning, sexual enjoyment, future perspective, systemic therapy, breast symptoms, arm symptoms, and hair loss assessed by the QLQ BR-23 were 76.4 (range: 16.67-100), 18.3 (range: 0-100), 33.3 (range: 0-100), 73.6 (range: 0-100), 30.5 (range: 0-90.5), 16.2 (range: 0-66.7), 23.45 (range: $0-77.8$ ), 32.7 (range: $0-100$ ), respectively.
Significant negative correlation was noted between the overall EORTC QLQ-C30 score and the decreasing age $(p=0.022)$. No significant difference was noted in the global health status $(p=0.41)$, physical function $(p=$ $0.96)$, role function $(p=0.42)$, emotional function $(p=$ $0.74)$, cognitive function $(p=0.30)$, and social function $(p=0.19)$ parameters in the two groups who underwent BCS versus mastectomy as reported by the EORTC QLQ-C30. The parameters assessed by the QLQ BR-23 such as body image $(p=0.37)$, sexual functioning ( $p=$ $0.17)$, sexual enjoyment $(p=0.28)$, future perspective $(p=0.94)$, systemic therapy $(p=0.81)$, breast symptoms $(p=0.46)$, arm symptoms $(p=0.18)$, and hair loss $(p=$ 0.859 ) were also similar in the two groups who underwent BCS compared with mastectomy (Table 2).

\section{Discussion}

This cross-sectional study evaluated the post-treatment QOL in Sri Lankan female patients diagnosed with breast cancer using the validated EORTC QLQ-C30 and BR-23 tools have shown substantially poor QOL in sexual functioning and enjoyment, breast and arm symptoms and hair loss domains while the impact on global health status including physical, social and emotional functions were minimal. The mean EORTC QLQ-C30 score of 68.8 indicated that our patients health related quality of life (HRQL) is comparable with average global figures (mean $61.8+/-24.6$ ) as well as previously published local figures (mean $50+/-24.3$ ) [12, 23]. However, our study did not demonstrate an association with the type of surgery and the post-treatment QOL of patients according to EORTC QLQ-C30 and QLQ-BR23 scores $(P>0.05)$. In addition, a negative correlation was observed with the overall EORTC QLQ-C30 score and the age $(p=0.022)$ where younger patients showed a significantly better QOL scores. This finding is different to that of most studies from the west which could be because the value of the intact breast is perceived differently in younger women than older women as younger women are more sexually active than older women unlike in the western world [24]. This is evident in regional studies which is keeping in with our findings [25].

A majority of previous studies investigating QOL with type of breast surgery from Western countries have shown conflicting results although most studies have shown BCS to be superior to mastectomy [15-18, 26, 27]. A study by Chow et al. on symptom burden and QOL in breast cancer patients treated with BCS versus mastectomy showed mastectomy patients to have a significantly lower QOL, lower physical and emotional wellbeing, higher pain, anxiety, drowsiness and loss of appetite compared with BCS [26]. However, in that study, the QOL was assessed using a different tool compared to the present study [26]. A study done in 
Table 1 Demographic and clinical characteristic of study participants

\begin{tabular}{|c|c|c|}
\hline Variables & Frequency & Percentage \\
\hline \multicolumn{3}{|l|}{$\overline{\text { Age }}$} \\
\hline$\leq 60$ years & 33 & $61.11 \%$ \\
\hline$>60$ years & 21 & $38.9 \%$ \\
\hline \multicolumn{3}{|l|}{ Marital status } \\
\hline Married & 51 & $94.4 \%$ \\
\hline Unmarried & 3 & $5.6 \%$ \\
\hline \multicolumn{3}{|l|}{ Educational level } \\
\hline Primary & 4 & $7.4 \%$ \\
\hline Secondary & 43 & $79.6 \%$ \\
\hline Graduate & 2 & $3.7 \%$ \\
\hline Postgraduate & 3 & $5.6 \%$ \\
\hline \multicolumn{3}{|l|}{ Occupation } \\
\hline Actively employed & 10 & $18.5 \%$ \\
\hline Retired/homemaker & 5 & $9.3 \%$ \\
\hline Not available & 39 & $72.22 \%$ \\
\hline \multicolumn{3}{|l|}{ Menopausal status } \\
\hline Premenopausal & 7 & $13.0 \%$ \\
\hline Postmenopausal & 46 & $85.2 \%$ \\
\hline \multicolumn{3}{|l|}{ Tumour size } \\
\hline $\mathrm{T} 1$ & 15 & $30.6 \%$ \\
\hline $\mathrm{T} 2$ & 27 & $55.1 \%$ \\
\hline T3 & 5 & $10.2 \%$ \\
\hline T4 & 2 & $4.1 \%$ \\
\hline \multicolumn{3}{|l|}{ Node positivity } \\
\hline NO & 17 & $37.0 \%$ \\
\hline $\mathrm{N} 1$ & 13 & $28.3 \%$ \\
\hline N2 & 11 & $23.9 \%$ \\
\hline N3 & 5 & $10.9 \%$ \\
\hline \multicolumn{3}{|l|}{ Metastasis } \\
\hline MO & 27 & $49.1 \%$ \\
\hline$M x$ & 12 & $21.8 \%$ \\
\hline \multicolumn{3}{|l|}{ Type of surgery } \\
\hline Breast conservation surgery & 19 & $35.2 \%$ \\
\hline Mastectomy & 33 & $61.1 \%$ \\
\hline \multicolumn{3}{|l|}{ Time elapsed following surgery } \\
\hline$>2$ years & 38 & $70.38 \%$ \\
\hline 2 years & 15 & $27.8 \%$ \\
\hline \multicolumn{3}{|l|}{ Axillary surgery } \\
\hline Sentinel lymph node biopsy & 16 & $29.6 \%$ \\
\hline Axillary lymph node dissection & 32 & $59.3 \%$ \\
\hline \multicolumn{3}{|l|}{ Adjuvant chemotherapy } \\
\hline Yes & 23 & $42.6 \%$ \\
\hline No & 9 & $16.7 \%$ \\
\hline No information & 22 & $40.7 \%$ \\
\hline
\end{tabular}


Table 1 Demographic and clinical characteristic of study participants (Continued)

\begin{tabular}{lll}
\hline Variables & Frequency & Percentage \\
\hline Adjuvant radiotherapy & 29 & $53.7 \%$ \\
Yes & 3 & $5.6 \%$ \\
No & 22 & $40.7 \%$ \\
No information & & $37 \%$ \\
Hormone Therapy & 20 & $22.2 \%$ \\
Yes & 12 & $40.7 \%$ \\
No & 22 & \\
No information & & \\
\hline
\end{tabular}

Germany by Engel et al. using similar assessment tools concluded that the patients undergoing BCS had better scores in most variables and had a significantly better overall QOL. In this study, mastectomy patients had lower body image, limited role function, less sexual activity, increased insecurity and had their day today activities affected to a greater extent [19].

Few long-term follow-up studies have shown no differences in body image, sexual function over time among patients who underwent BCS in comparison with mastectomy [15, 27]. A large prospective cohort study by Ganz et al. comparing patients undergoing BCS versus mastectomy found no significant differences in quality of life, psychosocial adjustment, rehabilitation needs, or mood [15]. Another large prospective cohort study by Browne et al. that analysed the association between complications and QOL after breast reconstruction and mastectomy showed that surgical complications had little or no association with the quality of life among patients who underwent mastectomy with or without reconstruction [27]. Furthermore, surgical complications did not have a significant impact on the their physical wellbeing scores [27]. The reasons behind the unexpected lack of improvement in quality of life after BCS may be explained by the fear of recurrence or the effects of post-operative radiotherapy. This could be further influenced by local sociocultural and educational factors as well as personal beliefs. Furthermore, absence of a deterioration of body image in our sample may also suggest the absence of a difference in QOL parameters in relation to type of surgery.

In comparison with the global values for QLQ-30 in women after breast cancer treatment, the role function, emotional function, and social function showed substantially better QOL values. However, compared to global parameters, the scores of BR-23 such as body image, sexual functioning and sexual enjoyment appear to be lower [23]. The reasons for these differences could be due to the sociocultural disparities in the local population compared to the women from the Western countries. Most evidence on QOL after breast cancer surgery are from the Western world where the 'value' of an intact breast may vary from Sri Lankan women due to differences in socio-cultural values and body image. Most women are reluctant to bring out these sensitive issues related to sexual function and enjoyment in the local context. Higher mean age of the study population (59 years) with a majority of the women being postmenopausal (85.2\%) might also have contributed to the observed lack of difference between mastectomy and BCS.

According to our findings, the low sores in breast related symptoms measured by BR-23 seems to be a major contributing factor for the lower QOL in breast cancer patients. Taking this into consideration, it is necessary to take measures to address the burden of breast related symptoms of these patients following surgery as these are easily preventable with adequate care. The HRQL of these patients may be improved by simple measures such as addressing sexual issues by referring them for counselling and prescribing topical applications, offering physiotherapy to alleviate arm symptoms, provision of wigs to combat hair loss following treatment. Furthermore, in the Sri Lankan context patients would be reluctant to bring out these sensitive issues themselves with the doctors. Provision of regular contact with the patients through trained cancer care nurses to recognize these issues and provide advice may help improve QOL in these domains which ultimately will help improve overall QOL. Sri Lanka is a country with a strong preventive health care system. With the increasing cancer burden, the healthcare policy makers should strengthen the public health system by incorporating cancer care nurses into the system and they can address the issues of these patients as they arise.

Our study was the first of its kind performed in the Sri Lankan context. The main limitations of this study is the smaller sample size which may not be representative, the inequality of age distribution and the absence of a control group. Majority of the sample being older women could also contribute to the QOL scores mainly due to the sociocultural factors coming into play in the local context. Several other contributors for morbidity 
Table 2 Analysis of factors associated with quality of life

\begin{tabular}{|c|c|c|c|c|c|c|c|}
\hline \multirow[t]{2}{*}{ Variables } & & \multicolumn{2}{|l|}{ Age } & \multicolumn{2}{|c|}{ Type of surgery } & \multicolumn{2}{|l|}{ Axillary surgery } \\
\hline & & $\begin{array}{l}\leq 60 \\
\text { years }\end{array}$ & $\begin{array}{l}>60 \\
\text { years }\end{array}$ & $\mathrm{BCS}$ & $\overline{\text { Mastectomy }}$ & $\begin{array}{l}\text { Sentinel lymph node } \\
\text { biopsy }\end{array}$ & $\begin{array}{l}\text { Axillary lymph node } \\
\text { dissection }\end{array}$ \\
\hline \multicolumn{8}{|l|}{ EORTC QLQ-C30* score } \\
\hline \multirow{3}{*}{$\begin{array}{l}\text { Global health } \\
\text { status }\end{array}$} & Median & 83.3 & 58.3 & 83.3 & 66.7 & 70.8 & 75 \\
\hline & Range & $8.3-100$ & $25-100$ & $25-100$ & $8.33-100$ & $8.33-100$ & $25-100$ \\
\hline & $p$ & 0.135 & & 0.414 & & 0.550 & \\
\hline \multirow[t]{3}{*}{ Physical function } & Median & 73.33 & 73.33 & 73.33 & 73.33 & 66.67 & 80 \\
\hline & Range & $33.3-100$ & $41.7-100$ & $\begin{array}{l}33.3- \\
100\end{array}$ & $33.3-100$ & $33.3-100$ & $33.3-100$ \\
\hline & $p$ & 0.531 & & 0.962 & & 0.181 & \\
\hline \multirow[t]{3}{*}{ Role function } & Median & 83.3 & 83.3 & 83.3 & 83.3 & 91.7 & 83.3 \\
\hline & Range & $0-100$ & $16.7-100$ & $\begin{array}{l}16.7- \\
100\end{array}$ & $0-100$ & $66.7-100$ & $16.7-100$ \\
\hline & $\mathrm{p}$ & 0.087 & & 0.429 & & 0.78 & \\
\hline \multirow[t]{3}{*}{ Emotional function } & Median & 91.7 & 75 & 91.7 & 75 & 91.7 & 91.7 \\
\hline & Range & $0-100$ & $16.7-100$ & $0-100$ & $0-100$ & $16.7-100$ & $16.7-100$ \\
\hline & $p$ & 0.587 & & 0.745 & & 0.759 & \\
\hline \multirow[t]{3}{*}{ Cognitive function } & Median & 83.3 & 83.3 & 83.3 & 83.3 & 83.3 & 83.3 \\
\hline & Range & $33.3-100$ & $50-100$ & $50-100$ & $33.3-100$ & $33.3-100$ & $50-100$ \\
\hline & $\mathrm{p}$ & 0.108 & & 0.309 & & 0.501 & \\
\hline \multirow[t]{3}{*}{ Social function } & Median & 100 & 100 & 100 & 100 & 100 & 100 \\
\hline & Range & $16.7-100$ & $0-100$ & $0-100$ & $16.7-100$ & $50-100$ & $0-100$ \\
\hline & $p$ & 0.27 & & 0.193 & & 0.81 & \\
\hline \multicolumn{8}{|l|}{ BR 23 Score ${ }^{* *}$} \\
\hline \multirow[t]{3}{*}{ Body image } & Median & 86.11 & 83.33 & 100 & 83.33 & 95.83 & 83.33 \\
\hline & Range & $16.7-100$ & $16.7-100$ & $\begin{array}{l}16.7- \\
100\end{array}$ & $41.7-100$ & $16.7-100$ & $16.7-100$ \\
\hline & $\mathrm{p}$ & 0.874 & & 0.375 & & 0.645 & \\
\hline \multirow[t]{3}{*}{ Sexual functioning } & Median & 16.7 & 0 & 16.7 & 8.3 & 16.7 & 0 \\
\hline & Range & $0-100$ & $0-33.3$ & $0-100$ & $0-100$ & $0-100$ & $0-100$ \\
\hline & $p$ & 0.145 & & 0.172 & & 0.236 & \\
\hline \multirow[t]{3}{*}{ Sexual enjoyment } & Median & 33.3 & 16.7 & 33.3 & 33.3 & 33.3 & 33.3 \\
\hline & Range & $0-100$ & $0-66.7$ & $0-100$ & $0-100$ & $0-100$ & $0-100$ \\
\hline & $p$ & 0.57 & & 0.283 & & 0.393 & \\
\hline \multirow[t]{3}{*}{ Future perspective } & Median & 100 & 66.7 & 100 & 100 & 83.3 & 100 \\
\hline & Range & $0-100$ & $0-100$ & $0-100$ & $0-100$ & $0-100$ & $0-100$ \\
\hline & $p$ & 0.227 & & 0.949 & & 0.595 & \\
\hline \multirow[t]{3}{*}{ Systemic therapy } & Median & 23.8 & 28.5 & 28.5 & 23.8 & 35.7 & 19.1 \\
\hline & Range & $0-90.4$ & $0-90.4$ & $0-85.7$ & $0-90.4$ & $9.5-90.4$ & $0-90.5$ \\
\hline & $\mathrm{p}$ & 0.636 & & 0.811 & & 0.009 & \\
\hline \multirow[t]{3}{*}{ Breast symptoms } & Median & 16.7 & 16.7 & 16.7 & 16.7 & 16.7 & 16.7 \\
\hline & Range & $0-66.7$ & $0-66.7$ & $0-66.7$ & $0-33.3$ & $0-66.7$ & $0-66.7$ \\
\hline & $p$ & 0.27 & & 0.469 & & 0.393 & \\
\hline \multirow[t]{3}{*}{ Arm symptoms } & Median & 22.2 & 22.2 & 11.1 & 22.2 & 22.2 & 22.2 \\
\hline & Range & $0-77.8$ & $0-66.7$ & $0-55.6$ & $0-77.8$ & $0-66.7$ & $0-77.8$ \\
\hline & $p$ & 0.689 & & 0.185 & & 0.84 & \\
\hline
\end{tabular}


Table 2 Analysis of factors associated with quality of life (Continued)

\begin{tabular}{|c|c|c|c|c|c|c|c|}
\hline \multirow[t]{2}{*}{ Variables } & & \multicolumn{2}{|l|}{ Age } & \multicolumn{2}{|c|}{ Type of surgery } & \multicolumn{2}{|l|}{ Axillary surgery } \\
\hline & & $\begin{array}{l}\leq 60 \\
\text { years }\end{array}$ & $\begin{array}{l}>60 \\
\text { years }\end{array}$ & $\mathrm{BCS}$ & Mastectomy & $\begin{array}{l}\text { Sentinel lymph node } \\
\text { biopsy }\end{array}$ & $\begin{array}{l}\text { Axillary lymph node } \\
\text { dissection }\end{array}$ \\
\hline \multirow[t]{3}{*}{ Hair loss } & Median & 0 & 33.3 & 16.7 & 0 & 66.7 & 0 \\
\hline & Range & $0-100$ & $0-100$ & $0-100$ & $0-100$ & $0-100$ & $0-100$ \\
\hline & $p$ & 0.084 & & 0.859 & & 0.009 & \\
\hline
\end{tabular}

* European organization for Research and Treatment of Cancer Quality of Life Questionnaire C30

** European organization for Research and Treatment of Cancer Quality of Life Questionnaire BR 23

following surgery for breast cancer such as sensory complaints of the ipsilateral arm, duration of disease, and a comparison before and after surgery was not considered in the present study which seem necessary in evaluating the QOL. Qualitative methods in future studies may provide further insight. Further prospective studies with larger sample sizes are deemed essential in the local context incorporating these other factors that may affect QOL among breast cancer patients.

\section{Conclusions}

Sexual functioning and enjoyment, breast and arm symptoms and hair loss contributed to poor QOL in women after treatment for breast cancer while the impact on global health status including physical, social and emotional functions were minimal. Type of surgery did not appear to be associated with QOL. Age was the only statistically significant factor associated with QOL, where younger patients showed a significantly better QOL. Measures should be implemented to help women with breast related symptoms especially sexual, arm and hair loss related symptoms which contribute significantly to poor QOL following surgery. Further studies with larger sample sizes will be helpful to confirm these findings and to identify strategies to improve QOL in these specific domains.

\section{Abbreviations}

QOL: Quality of life; BCS: Breast conservation surgery; HRQL: Health related quality of life; EORTC: European organization for Research and Treatment of Cancer

\section{Supplementary Information}

The online version contains supplementary material available at https://doi. org/10.1186/s12885-021-08055-5.

Additional file 1. STROBE Statement-Checklist of items that should be included in reports of cross-sectional studies.

\section{Acknowledgements}

A part of this study was presented at the Annual Academic Sessions of the Association of Surgeons of Great Britain \& Ireland in $2020[28,29]$. The paper has been published as a preprint [30].
Code availability

Not applicable.

\section{Authors' contributions}

RJ, AF and UJ contributed to concept and design of study, acquisition of data, analysis, interpretation of data, drafting the article and final approval of the version to be published. SS contributed to concept and design of study, revising it critically for important intellectual content; and final approval of the version to be published. All authors have read and approved the manuscript.

\section{Funding}

None

Availability of data and materials

The data used in the above analysis will be available on reasonable request from the corresponding author.

\section{Declarations}

Ethics approval and consent to participate

Ethics approval was obtained from the Ethics Review Committee of the Faculty of Medicine, University of Colombo, Sri Lanka (EC-17-126). All patients gave informed written consent before participating in this study.

\section{Consent for publication}

Not obtained.

\section{Competing interests}

All authors declare that there are no competing interests

Received: 16 October 2020 Accepted: 17 March 2021

Published online: 23 March 2021

\section{References}

1. World Health Organization. International Agency for Research on Cancer. Cancer Today - GLOBOCAN. Accessed from: https://gco.iarc.fr/today/home. Accessed 03 Jan 2021.

2. Fernando A, Jayarajah U, Prabashani S, Fernando EA, Seneviratne SA. Incidence trends and patterns of breast cancer in Sri Lanka: an analysis of the national cancer database. BMC Cancer. 2018;18(1):482. https://doi.org/1 0.1186/s12885-018-4408-4

3. Jayarajah U, Varothayan S, Jayasinghe R, Seneviratne S: Present status of cancer burden in Sri Lanka based on GLOBOCAN estimates. South Asian J Cancer 2021, 10:In Press.

4. Kesson EM, Allardice GM, George WD, Burns HJ, Morrison DS. Effects of multidisciplinary team working on breast cancer survival: retrospective, comparative, interventional cohort study of 13722 women. BMJ. 2012;344: e2718.

5. Basnayake $\mathrm{O}$, Jayarajah U, Seneviratne S. Management of axilla in breast cancer: the past, present and the future. Sri Lanka Journal of Surgery. 2018: 36(4).

6. Bertan FC, EKd C. Qualidade de vida e câncer: revisão sistemática de artigos brasileiros. Psico (Porto Alegre). 2009:366-72. 
7. Nounou MI, ElAmrawy F, Ahmed N, Abdelraouf K, Goda S, Syed-Sha-Qhattal $\mathrm{H}$ : Breast Cancer: Conventional Diagnosis and Treatment Modalities and Recent Patents and Technologies. Breast Cancer 2015, 9s2:BCBCR.S29420.

8. Aaronson N. Quality of life and clinical trials. Lancet. 1995;346(8966):1-2.

9. Barbosa PA, Cesca RG, Pacífico TED, Leite ICG. Quality of life in women with breast cancer, after surgical intervention, in a city in the zona da Mata region in Minas Gerais, Brazil. Revista Brasileira de Saúde Materno Infantil. 2017;17(2):385-99. https://doi.org/10.1590/1806-93042017000200010.

10. Aaronson NK, Ahmedzai S, Bergman B, Bullinger M, Cull A, Duez NJ, Filiberti A, Flechtner H, Fleishman SB, de Haes JC. The European Organization for Research and Treatment of Cancer QLQ-C30: a quality-of-life instrument for use in international clinical trials in oncology. JNCl. 1993;85(5):365-76. https://doi.org/10.1093/jnci/85.5.365.

11. Fas M, Mrdo L, Ms M. Validity, reliability and understanding of the eortc-c30 and eortcBr23, quality of life questionnaires specific for breast cancer. Rev Bras Epidemiol. 2013;16(2):352-63.

12. Jayasekara H, Rajapaksa LC, Aaronson NK. Quality of life in cancer patients in South Asia: psychometric properties of the Sinhala version of the EORTC QLQ-C30 in cancer patients with heterogeneous diagnoses. Qual Life Res. 2008;17(5):783-91. https://doi.org/10.1007/s11136-008-9345-2.

13. National Institutes of Health: Treatment of early stage breast cancer. In: NIH Consensus Development Conference: 1991; 1991.

14. Pinto A, Faiz O, Davis R, Almoudaris A, Vincent C. Surgical complications and their impact on patients' psychosocial well-being: a systematic review and meta-analysis. BMJ Open. 2016:6(2).

15. Ganz PA, Anne Schag CC, Lee JJ, Polinsky ML, Tan SJ. Breast conservation versus mastectomy. Is there a difference in psychological adjustment or quality of life in the year after surgery? Cancer. 1992;69(7):1729-38. https:// doi.org/10.1002/1097-0142(19920401)69:7<1729::AID-CNCR2820690714>3.0 $\mathrm{CO} ; 2-\mathrm{D}$.

16. Kiebert G, De Haes J, Van de Velde C. The impact of breast-conserving treatment and mastectomy on the quality of life of early-stage breast cancer patients: a review. J Clin Oncol. 1991;9(6):1059-70. https://doi.org/1 0.1200/JCO.1991.9.6.1059.

17. Rietman JS, Dijkstra PU, Hoekstra HJ, Eisma WH, Szabo BG, Groothoff JW, Geertzen JH. Late morbidity after treatment of breast cancer in relation to daily activities and quality of life: a systematic review. EJSO. 2003;29(3):22938. https://doi.org/10.1053/ejso.2002.1403.

18. Freitas-Silva R, Conde DM, Rd F-J, Martinez EZ. Comparison of quality of life, satisfaction with surgery and shoulder-arm morbidity in breast cancer survivors submitted to breast-conserving therapy or mastectomy followed by immediate breast reconstruction. Clinics. 2010;65(8):781-7. https://doi. org/10.1590/S1807-59322010000800007.

19. Engel J, Kerr J, Schlesinger-Raab A, Sauer H, Hölzel D. Quality of life following breast-conserving therapy or mastectomy: results of a 5-year prospective study. Breast J. 2004;10(3):223-31. https://doi.org/10.1111/j.1 075-122X.2004.21323.x.

20. EORTC Quality of Life Group. EORTC QLQ-C30 (version 3) Accessed from: https://www.eortc.org/app/uploads/sites/2/2018/08/Specimen-QLQC30English.pdf. Accessed 03 Jan 2021.

21. EORTC Quality of Life Group. EORTC QLQ-BR23. Accessed from: https:// www.eortc.org/app/uploads/sites/2/2018/08/Specimen-BR23-English-1.1.pdf. Accessed 03 Jan 2021.

22. Fayers P, Aaronson NK, Bjordal K, Sullivan M: EORTC QLQ-C30 scoring manual: European Organisation for Research and Treatment of Cancer; 1995.

23. Scott NW, Fayers P, Aaronson NK, Bottomley A, de Graeff A, Groenvold M, Gundy C, Koller M, Petersen MA, Sprangers MA: EORTC QLQ-C30 reference values manual. 2008.

24. Bantema-Joppe EJ, de Bock GH, Woltman-van lersel M, Busz DM, Ranchor AV, Langendijk JA, Maduro JH, van den Heuvel ER. The impact of age on changes in quality of life among breast cancer survivors treated with breastconserving surgery and radiotherapy. Br J Cancer. 2015;112(4):636-43. https://doi.org/10.1038/bjc.2014.632

25. Park B-W, Lee S, Lee AR, Lee K-H, Hwang SY. Quality of life differences between younger and older breast cancer patients. J Breast Cancer. 2011; 14(2):112-8. https://doi.org/10.4048/jbc.2011.14.2.112.

26. Chow R, Pulenzas N, Zhang L, Ecclestone C, Leahey A, Hamer J, DeAngelis C, Bedard G, McDonald R, Bhatia A. Quality of life and symptom burden in patients with breast cancer treated with mastectomy and lumpectomy.
Support Care Cancer. 2016;24(5):2191-9. https://doi.org/10.1007/s00520-01 5-3027-8.

27. Browne JP, Jeevan R, Gulliver-Clarke C, Pereira J, Caddy CM, van der Meulen $J \mathrm{H}$. The association between complications and quality of life after mastectomy and breast reconstruction for breast cancer. Cancer. 2017; 123(18):3460-7. https://doi.org/10.1002/cncr.30788.

28. Epa T, Fernando A, Colonne S, Jayarajah U, Seneviratne S. Long term posttreatment psychological outcomes in breast cancer patients from a tertiary care surgical unit in a developing country in South Asia. Br J Surg. 2020;107: $153-4$.

29. Epa T, Fernando A, Colonne S, Jayarajah U, Seneviratne S. Long term posttreatment quality of life in breast cancer patients from a tertiary care surgical unit in a developing country in South Asia. Br J Surg. 2020;107:154-4.

30. Jayasinghe R, Fernando A, Jayarajah U, Seneviratne S. Post Treatment Quality of Life among Sri Lankan Women with Breast Cancer. 2020. https:// doi.org/10.21203/rs.21203.rs-108190/v108191.

\section{Publisher's Note}

Springer Nature remains neutral with regard to jurisdictional claims in published maps and institutional affiliations.
Ready to submit your research? Choose BMC and benefit from:

- fast, convenient online submission

- thorough peer review by experienced researchers in your field

- rapid publication on acceptance

- support for research data, including large and complex data types

- gold Open Access which fosters wider collaboration and increased citations

- maximum visibility for your research: over $100 \mathrm{M}$ website views per year

At $\mathrm{BMC}$, research is always in progress.

Learn more biomedcentral.com/submissions 